\title{
Bridging Departmental Communication Gaps in Quasi-Institutions: A Case Study of ZESCO Limited
}

\author{
Joan Mumba' ${ }^{*}\left(\mathbb{D}\right.$, Jackson Phiri² $^{2}$ \\ ${ }^{1}$ Graduate School of Business, University of Zambia, Lusaka, Zambia \\ ${ }^{2}$ Department of Computer Science, School of Natural Sciences, University of Zambia, Lusaka, Zambia \\ Email: *joanmumba@yahoo.com, jackson.phiri@cs.unza.zm
}

How to cite this paper: Mumba, J. and Phiri, J. (2019) Bridging Departmental Communication Gaps in Quasi-Institutions: A Case Study of ZESCO Limited. Open Journal of Business and Management, 7, 20092019.

https://doi.org/10.4236/ojbm.2019.74138

Received: October 7, 2019

Accepted: October 21, 2019

Published: October 24, 2019

Copyright $\odot 2019$ by author(s) and Scientific Research Publishing Inc. This work is licensed under the Creative Commons Attribution International License (CC BY 4.0).

http://creativecommons.org/licenses/by/4.0/ (c) (i) Open Access

\begin{abstract}
Communication is seen as the key factor in the success of any organization but when it comes to effective communication, there are certain barriers that every organization faces. Large organisations have deficiencies in their decentralized departments especially when dealing with large volume of clientele whose needs are divided amongst their personal and organizational obligations. Hence communication gaps leading to conflicts and information breakdown among employees in the organization. The ramifications of these conflicts and broken information flow has been poor performance of team members, negative impact on general productivity, inefficiencies in responding to clients' demands, bad publicity for the company and lose of million in service delay. It is against this background that the aim of this study was to identify the major factors leading to intra and inter departmental communication gaps in Quasi-Institutions and come up with a model in order to address these communication gaps. The study used a quantitative study approach based on a sample space of 150 self-administered survey questionnaires with 83\% response from Quasi-Government Institutions. Quantitative data was analysed using Chi-square and P-value statistical analysis with Statistical Package for the Social Sciences (SPSS) software tool. The study found that there are existing communication gaps due to conflicts within and between departments. This was validated by the results from chi-square test which yielded a chi-square value of 4.419 and the p-value of 0.036 . The difference was statistically significant at 4.419 , because p-value (0.036) was less than alpha level $(\alpha=0.05)$. Hence, the results suggested that respondents deal with conflict at their place of work. Further results revealed that, personal conflicts are not always sorted out quickly by supervisors and managers, poor inter-personal communication, and poor inter-departmental communications
\end{abstract}


are the causes of the existing communication gaps. The study therefore recommended that management should provide conflict resolution training which gives employees more assurance in their capability to resolve both personal and professional conflicts.

\section{Keywords}

Communication, Conflict, Departments, Gaps, Model, Quasi-Institutions

\section{Introduction}

Communication is the glue that holds a society together. The ability to communicate enables people to form and maintain personal relationships. The quality of such relationships depends on the caliber of communication between the parties [1]. Communication is a vital part of personal life and is also important in business, education, and any other situations where people encounter each other [2]. Therefore, Communication is important for any organization to function effectively. Employees should feel that they can easily communicate with their team members in the department as well as upper management because this contributes to productivity and overall results [3]. Communication is the process of sharing ideas, information, and messages with others in a particular time and place. Communication includes writing and talking, as well as nonverbal communication (such as facial expressions, body language, or gestures), visual communication (the use of images or pictures, such as painting, photography, video or film) and electronic communication (telephone calls, electronic mail, cable television, or satellite broadcasts).

\section{Literature Review}

Communication is the most important of all entrepreneurial skills. This is because the destiny of every business depends on the quality of relationships within the organisation. The employee's ability to transmit information helps both internal and external stakeholders feel they can communicate with and ultimately trust the company [4].

\subsection{Communication Gaps That Exist in Organizations and Companies}

There are a number of gaps that exist in organizations and companies where communication is concerned. Some of these are human made while others are system and bureaucratic made. This sub theme will discuss studies on the communication gaps in different companies and organizations in the world.

\subsubsection{Attitudinal Barriers}

A study conducted by [5] in Ethiopia found that there were attitudinal barriers which existed within the operations of major companies. The study asserts that 
these were communication barriers which were held by different people towards others. For instance, if a manager has a poor attitude towards the junior staff, communication between them may not be effective. More especially, if the manager has the tendency of imposing things on the junior staff or intimidating them, the junior staff may not be free to share information to their superiors (managers). Thus, [6] expands that some members in the departments have the negative attitude towards the employees who do not belong to their department.

\subsubsection{Behavioral Barriers}

A study by [7] on communication barriers in mega factories found that these communication barriers occur when individuals display a behaviour which may prevent them from knowing more information from other people. The study further indicated that when an individual has stereotyping views towards other people, they make conclusions about those people before they acquire more information from them. For instance, if a manager stereotypes against the female workers to be lazy, the manager may be treating every female as a lazy individual, even before he/she sees the performance of such individuals. In the same view, a study by [8] found that there is also information gap when the departments stereotype against each other. That is because some departments have the tendency of judging other departments based on the past experiences and other departments do not want to take advice from others because of their rankings.

\subsubsection{Cultural Barriers}

[9] Conducted a study in a multiracial factory and claims that differences in cultural values, beliefs and attitudes may result in miscommunication. In this context, a study by [10] found that the work cultures of some departments are barriers to smooth communication because some departments have long and complicated channels of communication. In addition, [11] emphasises that when the departments lack the spirit of urgency, they usually delay to communicate the information to the other relevant departments.

\subsubsection{Language Barriers}

[7] State that language barriers occur when people are speaking two or more different languages which are not clear to each other. For instance, when a Chinese is speaking to an English person on a genuine complaint over goods and services, due to pronunciation and intonation, the two may not understand each other well thereby creating barriers in communication flow. The study further found that language barriers may also occur when people are speaking the same language, but different levels of languages are used in a conversation. For instance, when two people are speaking English but a customer care officer is using jargons and ambiguous words while the client is using slang, the two may not understand each other.

\subsubsection{Environmental Barriers}

[5] Asserts that these barriers originate from the environment in which commu- 
nication takes place from. For instance, a workplace may be too noisy such that it becomes difficulty for people to understand each other. In addition, distractors such as televisions or events outside the workplace may also negatively affect communication. It further adds that for written communication, barriers to effective communication may be the inclusion of irrelevant information, causing a reader to lose focus. A study by [12] asserts that the environmental distractors to effective communication may also refer to the delays in approving the letters of communication between two or more departments.

\subsubsection{People-People Gaps}

[13] Explain that this means that, when one employee needs information from another in order to execute a task, the transfer of information becomes a critical part of the business process. When employees fail to pass on the appropriate information to their counterparts in a timely, concise, and accurate manner, inefficiencies and errors can occur. People gaps can occur either within a single department, or across departments.

\subsubsection{People-System Gaps}

Thus, [14] in his study articulates that people-system gaps occur when the information a person needs from a system is not easily accessible, readily available, or accurate. When people-system gaps occur, systems fail to provide people with the information they need to do their jobs and inefficiencies occur. He concluded that people-system gaps occur when people fail to enter the appropriate information back into systems.

\subsubsection{System-System Gaps}

In another study, [15] claims that often times, system-system gaps occur when a business process is cross-departmental or cross functional. Sharing information among systems from different departments, or among multiple systems in different areas, can present a communication challenge. When different departments or business units use different information technology (IT) systems, data must be entered and re-entered, leaving room for data entry mistakes and creating gaps between different parts of an organisation.

\subsection{Thayer's Organizational Communication Model}

This model creates a link between personal Business Communication and organizational structure. Figure 1 shows that the attempt to accomplish any task through personal communication greatly influences the process of organizational communication as proposed by Thayer. Four levels are mentioned in this Business Communication Model, such as-intra-personal or individual, interpersonal, organizational and technological.

This model also shows how a person's does communication functions in organizational level. The behavior of sender and receiver can be influenced by four elements biological, psychological, social and technological. Actually, this model shows how the communication process is affected by a person in organizational 


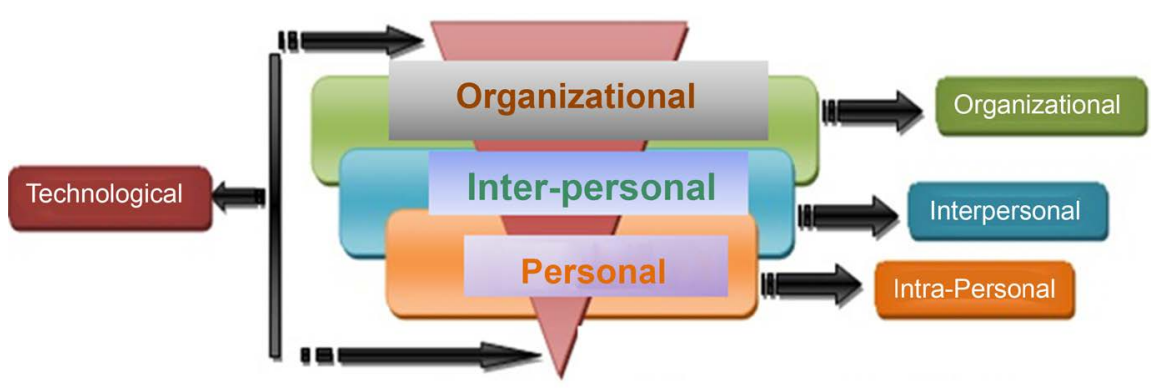

Figure 1. Thayer's organizational communication model.

atmosphere. Thayer has shown that the attempt to accomplish any task through personal communication greatly influences the process of organizational communication.

\section{Research Methodology}

Quantitative survey design was used in this study. The study population comprised of all employees of the Power Utility Company which is quasi-government based in Lusaka, Zambia. The sample was purposively selected targeting all employees in the company to ensure that all departments were included in the sample size. The sample size was determined by the following function:

$$
n=N /\left[1+N(e)^{2}\right]
$$

Equation (1) was used to determine the sample size, where $\mathrm{n}$ is the sample size, $\mathrm{N}$ is the population and $\mathrm{e}$ is the level of precision Based on $10 \%$ precision level, it gave a sample size of 150 . A total of 150 questionnaires were distributed which had $83 \%$ response rate from the targeted respondents.

\section{Data Collection, Analysis and Interpretation}

The data was analyzed using the statistical package for social science [16]. The statistical analysis was based on Chi-square and P-Values. The research model that was used highlights the relationship between five variables that contribute to factors of communication gap within and between departments in an organization. The factors among them include "personal conflicts between department managers and undertrained employees"; "demoralized employees and broken information flow"; "cultural diversity in the workplace and employees disengaged". Furthermore other factors include; "poor leadership and limited feedback"; and "unclear objectives of roles for staff". The study looked at these factors in relation to their impact on department communication gaps in quasi-institutions. This was in an effort to bridging the existing communication gaps in the power utility firm.

\section{Results and Discussions}

The section looks at the findings based on the model used in the study. Correlation and P-Values were used in the analysis of the results. 


\subsection{Basic Statistical Analysis}

In this study majority of the respondent (57.6\%) were female while (42.4\%) were male as highlighted in Figure 2. Results in Figure 3 show that $69.60 \%$ of the respondents were married, $11.20 \%$ were divorced, $14.80 \%$ were single, and $4.80 \%$ were others. These findings indicate majority of respondents were married. As for the respondents who participated in the study, $41.6 \%$ of them were aged between 21 and 30 years, 29.6\% of them were aged between 31 and 40 years, $17.6 \%$ of them were aged between 41 and 50 years, $7.2 \%$ of them were aged 51 between 60 years, and $4.0 \%$ of them were 60 years and above. These findings indicate that majority of the respondents who participated in this study were between 21 and 30 years and are therefore knowledgeable enough to provide information relevant to the study as shown in Figure 4. On education the results in Figure 5 show that the majority of the respondents had a diploma qualification at $62.4 \%, 28.8 \%$ at degree level, while $6.4 \%$ had elementary qualification below a diploma with $2.4 \%$ of respondents having postgraduate. These findings indicate majority of respondents had attained Diploma and are therefore knowledgeable enough to provide information relevant to the study. Further results revealed that the respondents who participated in the study, 27.2\% were Customer service officers, $24.8 \%$ were Cashiers, $15.2 \%$ were Media liaison

\section{Gender Distribution of Respondents}

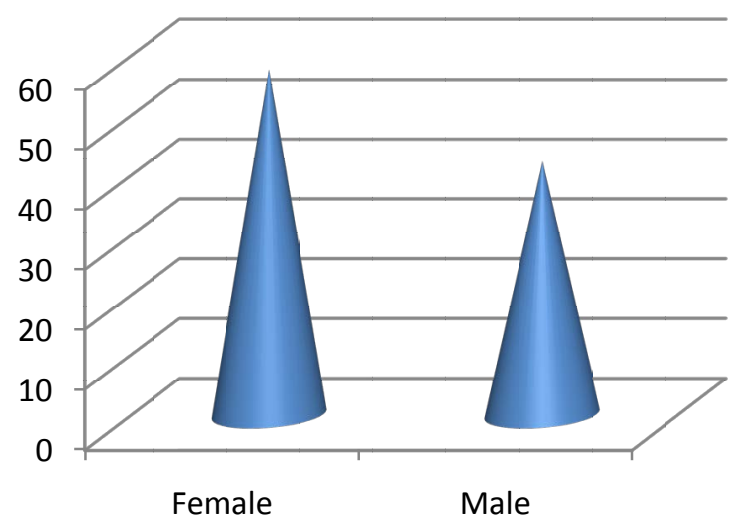

- Gender Distribution of Respondents

Figure 2. Gender distribution of respondents.

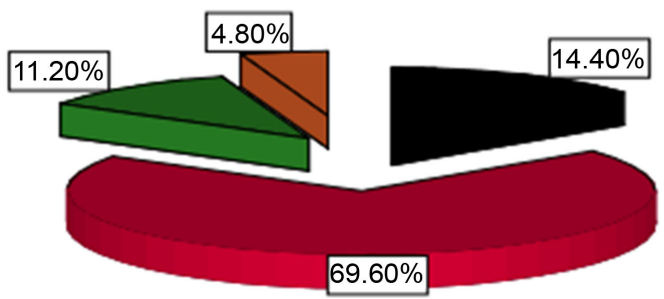

Single

Married

Divorced

$\square$ Other

Figure 3. Marital status of respondent. 


\section{Age Group Distribution of Respondents}

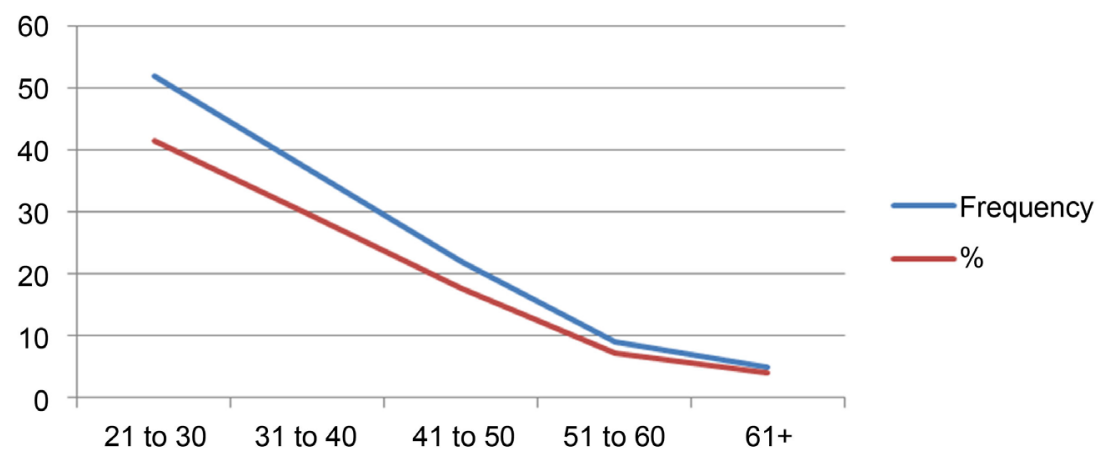

Figure 4. Age group distribution of respondents.

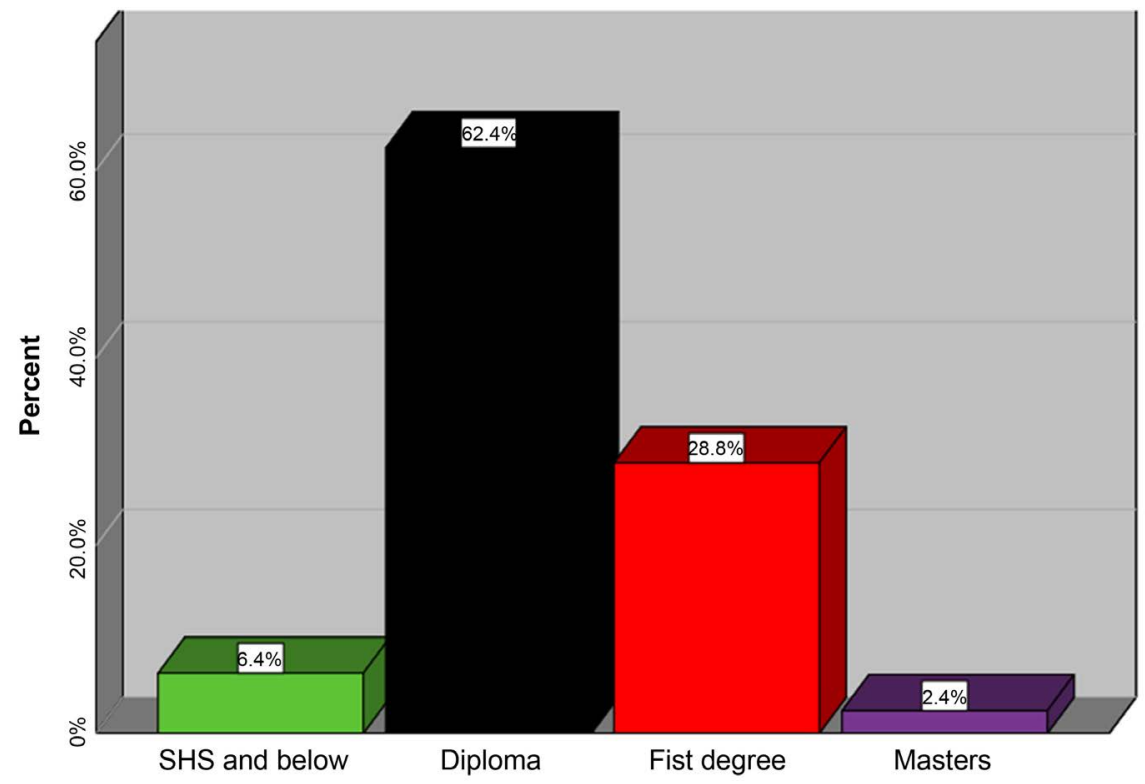

Figure 5. Level of education distribution of respondents.

officers, $8.8 \%$ were Public relation officers, $4.8 \%$ were in Business development, $6.4 \%$ were Senior marketing officers, $5.6 \%$ were Marketing officers, $0.8 \%$ were Managers, $2.4 \%$ were Management secretaries, and $4.0 \%$ general customer service staff. This suggests that the majority of the respondents who participated in the study were Customer service officers according to Figure 6.

\subsection{Dealing with Conflict at Work}

Chi-square and P-Values test were analysed through the use of the Research Model, to establish if there exists relationship between two variables. In the segment of this study, the relationship between the two variables (conflicts between department managers \& undertrained employees [independent variable] and communication gaps between departments [dependent variable]) was examined. In order to achieve this, the respondents were asked to indicate if they deal with 


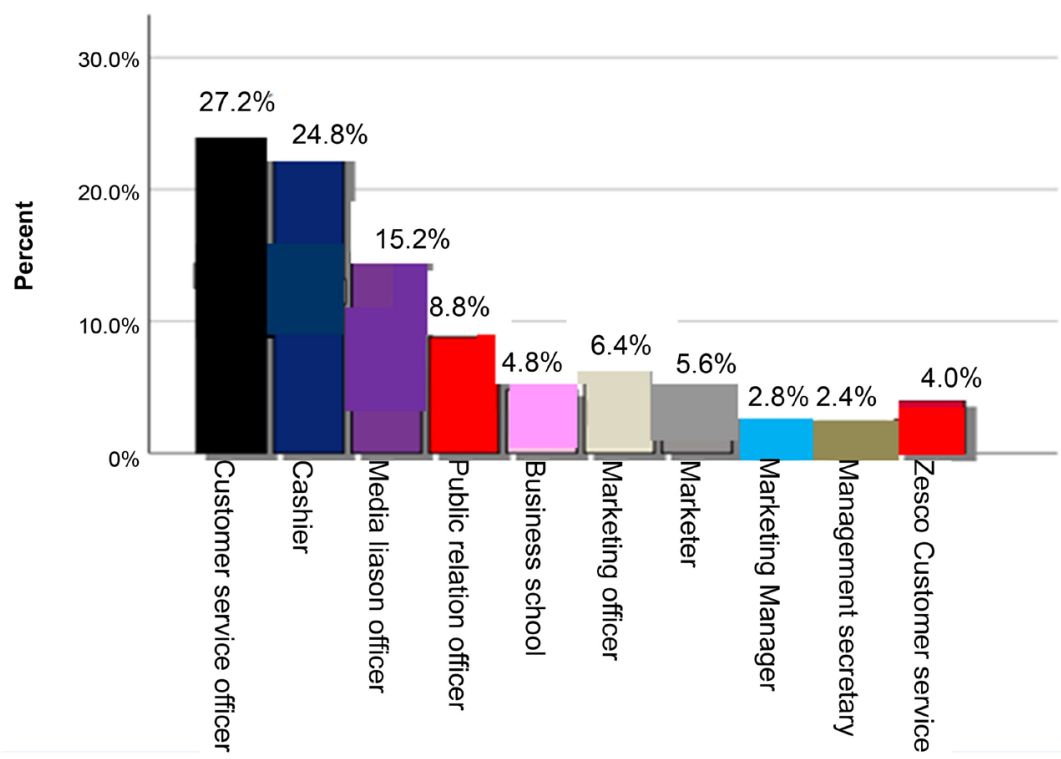

Figure 6. Occupation distribution of respondents.

conflict at their workplace. The findings from the chi-square test as shown in Table 1 yielded a chi-square value of 4.419 and the p-value was 0.036 . The difference was statistically significant at 4.419 , because p-value (0.036) was less than alpha level $(\alpha=0.05)$. Hence, the results suggested that respondents deal with conflict at their place of work between department managers and undertrained employees.

\subsection{Conflict between Departments in the Company}

Here the researcher sought to find out if there is conflict between departments in the company. The results from chi-square test as shown in Table 2 yielded a chi-square value of 3.827 and the p-value was 0.02 . The difference was statistically significant at 3.827 , because p-value $(0.02)$ was less than alpha level $(\alpha=$ $0.05)$. Hence, the results suggested that respondents experience conflict between departments in their company.

\subsection{Poor Inter-Personal Communication Is the Main Cause of Conflicts in Departments}

Chi-square and $\mathrm{P}$-value was tested on finding out if poor inter-personal communication is the main cause of conflicts in departments. The findings in the Chi-square Test yielded a Chi-square value of 5.073 and the p-value was 0.024. The difference was statistically significant at 0.24 , because the p-value $(0.024)$ was less than alpha level $(\alpha=0.05)$. Hence, the results suggested that poor inter-personal communication is the main cause of conflicts within departments.

\subsection{Poor Inter-Departmental Communication Is the Main Cause of Conflicts between Departments}

The statistical analysis was further tested on establishing if poor inter-departmental 
Table 1. Dealing with conflict at work.

\begin{tabular}{cccccc}
\hline \multicolumn{7}{c}{ Chi-Square Tests } \\
& Value & df & $\begin{array}{c}\text { Asymptotic } \\
\text { Significance (2-sided) }\end{array}$ & $\begin{array}{c}\text { Exact Sig. } \\
\text { (2-sided) }\end{array}$ & $\begin{array}{c}\text { Exact Sig. } \\
\text { (1-sided) }\end{array}$ \\
\hline Pearson Chi-Square & $4.419^{\mathrm{a}}$ & 1 & 0.036 & & \\
Continuity Correction ${ }^{\mathrm{b}}$ & 3.689 & 1 & 0.055 & & \\
Likelihood Ratio & 4.450 & 1 & 0.035 & 0.046 & 0.027 \\
Fisher's Exact Test & & & & & \\
Linear-by-Linear Association & 4.384 & 1 & 0.036 & & \\
N of Valid Cases & 125 & & & & \\
\hline
\end{tabular}

Table 2. Conflict between departments in their company.

\begin{tabular}{cccccc}
\hline \multicolumn{7}{c}{ Chi-Square Tests } \\
\hline & Value & df & $\begin{array}{c}\text { Asymptotic } \\
\text { Significance (2-sided) }\end{array}$ & $\begin{array}{c}\text { Exact Sig. } \\
\text { (2-sided) }\end{array}$ & $\begin{array}{c}\text { Exact Sig. } \\
\text { (1-sided) }\end{array}$ \\
\hline Pearson Chi-Square & $3.827^{\mathrm{a}}$ & 1 & 0.020 & & \\
Continuity Correction ${ }^{\mathrm{b}}$ & 2.837 & 1 & 0.092 & & \\
Likelihood Ratio & 4.513 & 1 & 0.034 & 0.039 & \\
Fisher's Exact Test & & & & & \\
Linear-by-Linear Association & 3.796 & 1 & 0.051 & & \\
N of Valid Cases & 125 & & & & \\
\hline
\end{tabular}

communication is the main cause of conflicts between departments. Results in the chi-square test yielded a chi-square value of 0.012 and the p-value was 6.073. The difference was statistically significant at 0.012 , because the p-value $(0.012)$ was less than alpha level $(\alpha=0.05)$. Hence, the results suggested that poor inter-departmental communication is the main cause of conflicts between departments.

\section{Conclusion}

Based on the findings, it can be concluded that there are some existing communication gaps within and between departments at ZESCO with regards to managers not exploring conflicts to find a lasting solution that meet everyone's needs, personal conflicts are not always sorted out quickly by supervisors and managers, poor inter-personal communication, and poor inter-departmental communication between departments. The study also established that employees are demoralized due to conflict in departments, poor leadership skills from management, employees not being satisfied with the communication procedure in their department, and poor information sharing from supervisors in their departments. The findings therefore, validated the research model that was used in this study. 


\section{Limitations}

Limitations in any research are inevitable, so just like any other research; this study also encountered some limitations. Limitations of the study refer to those factors of research design or methodology that can influence the interpretation or application of the findings of the study [17]. Data quality constraints associated with quantitative research are highlighted by [18] as prone to misinterpretation, difficulties in getting in-depth information, tend to be artificial and requires high levels of literacy by respondents. The study did not cover ZESCO (power utility firm) branches in other parts of the country other than Lusaka to understand if the results are applicable across the organization. Sample size was determined using purposive sampling, instead of random sampling to enable generalization of research findings. This study used descriptive survey instead of mixed methods and results may be limited.

\section{Recommendations}

From the results of the study, as well as the research gaps noted in the literature review, the study recommends the following:

- Provide conflict resolution training which gives people more assurance in their capability to resolve both personal and professional conflict.

- Provide communication skills training for employees in order to increase their ability to communicate effectively with a diverse range of individuals, and manage the communication problems that are often at the heart of organizational conflict.

- Provide conflict mediation training for leaders so that organizational leaders should improve their conflict mediation skills and help employees resolve the conflicts that will inevitably arise.

\section{Acknowledgements}

The author would like to acknowledge the special support rendered by everyone who took part in the actual administration of the questionnaires and all those who participated in the study.

\section{Conflicts of Interest}

The authors declare no conflicts of interest regarding the publication of this paper.

\section{References}

[1] Brennan, J. (1974) The Conscious Communicator: Making Communication Work in the Workplace. Addison-Wesley Publishing Co, Reading, MA.

[2] http://www.wikipedia.org/wiki/Communication

[3] Lewis, H. (1974) Communication Barriers between Educated and Uneducated Persons. Liter Work, 3, 29-34.

[4] Charles, K. (1998) Peak Performance the Art of Communication. Black Enterprise, 
117-121.

[5] Tannen, D. (2013) You Just Don't Understand. William Morrow/Harper Collins, New York.

[6] Conrad, C. (1994) Strategic Organizational Communication-Toward the Twenty-First Century. Harcourt Brace College Publishers, Fort Worth, TX.

[7] Newstrom, J.W. and Devis, K. (2013) Organizational Behaviour. McGraw-Hill, New Delhi.

[8] Beverly, M.H. (2005) Communication within a workplace-Master of Science in Training and Development. University of Wiscousin-Stout, Menomonie, WI.

[9] Luthans, F. (2010) Organizational Behaviour. McGraw-Hill, New Delhi.

[10] Clernons, J. (2003) Avoiding a Communication Breakdown: Keeping Employees Informed Benefits Business. Black Enterprise, 46-50.

[11] D’Aprix, R. (1996) Communicating for Change: Connecting the Workplace with the Marketplace. Jossey-Bass Publishers, San Francisco, CA.

[12] Holtz, S. (2004) Corporate Conversations: A Guide to Crafting Effective and Appropriate Internal Communications. Arnacom, New York.

[13] Reina, D.S. and Reina, M.L. (2005) Trust and Betrayal in the Workplace: Building Effective Relationships in Your Organization. Berrett-Koehler Publishers, Inc., San Francisco, CA.

[14] Schonfeld, E. (1994) Communication Goes Flat. Fortune, 16-20.

[15] Alessandra, T. and Hunsaker, P. (1993) Communication at Work. Fireside, Simon, and Schuster, New York.

[16] IBM Corp (2015) IBM SPSS Statistics for Windows, Version 23.0. IBM Corp, Armonk, NY.

[17] Yin, R. (2009) Case Study Research: Design and Methodology. Sage Publication, Thousand Oak, CA.

[18] Saunders, M.L. (2012) Research Methods for Business Students. 6th Edition, Pearson, Harlow. 